\title{
ANALISIS KEPUASAAN PELANGGAN JASA DELIVERY ORDER LAMONGAN DENGAN MENGGUNAKAN METODE SERVICE QUALITY
}

\author{
*(Diah Ayu Novitasari ${ }^{1}$, Septyan Budy Cahya ${ }^{2}$ \\ Prodi Manajemen, Fakultas Ekonomi, Universitas Islam Lamongan \\ $\mathrm{Jl}$. Veteran No.53A Lamongan \\ Telp. ( 0322 ) 324706, Faks. ( 0322 ) 324706 \\ Email :jpim.unisla@gmail.com
}

\begin{abstract}
ABSTRAK
Jasa pelayanan delivery order yang semakin banyak di kota Lamongan membuat persaingan semakin ketat dalam mendapatkan pelanggan. Usaha yang dapat dilakukan untuk mendapatkan pelanggan dan menjadi Jasa pelayanan delivery order yang terbaik dalam memberikan pelayanan terhadap pelanggan adalah dengan mengetahui hal-hal yang diharapkan oleh pelanggan, dan mengetahui persepsi pelanggan terhadap jasa pelayanan yang telah diberikan. Tujuan dari penelitian ini untuk mengetahui kesenjangan antara harapan dengan kenyataan dari pelayanan yang dirasakan pelanggan jasa delivery order. Analisis yang digunakan dalam penelitian ini adalahanalisis gap pada lima dimensi service qualityyaitu dimensi Tangible, Reliability, Responsiveness, Assurance dan Emphaty, untuk mengetahui dimensi serta variabel dominan yang dapat diusulkan sebagai prioritas perbaikan. Hasil penelitian menunjukkan bahwanilai negatif tertinggi adalah pada ketersediaan informasi invoice yang diberikan melalui whatsapp dan keyakinan dan ketepatan pembayaran sesuai dengan invoice. Kedua hal ini harus diperbaiki agar dapat meningkatkan kepuasaan pelanggan. Jika kepuasaan pelanggan meningkat maka akan semakin banyak pelanggan yang menggunakan jasa pelayanan delivery order di kota Lamongan.
\end{abstract}

Kata Kunci : Service Quality, Analisis Gap, Kepuasaan Pelanggan, Pelayanan.

\section{PENDAHULUAN}

Teknologi yang semakin berkembang di era globalisasi ini semakin memudahkan masyarakat dalam menjalani kehidupannya. Salah satu hal yang memudahkan masyarakat adalah terpenuhinya kebutuhan masyarakat dengan memanfaatkan jasa pelayanan secara online. Beragam aplikasi jasa pelayanan yang dapat dijalankan secara online semakin diminati oleh masyarakat terutama bagi masyarakat yang memiliki waktu terbatas. Mulai dari kebutuhan jasa kendaraan, pengiriman barang, pengiriman makanan, kebersihan, bahkan jasa massage atau pijat.

Di kota - kota besar jasa pelayanan yang sering digunakan adalah Grab dan Gojek. Namun Grab dan Gojek belum dapat diakses di kota- kota kecil. Hal ini memunculkan ide pengusaha untuk menciptakan jasa pelayanan tanpa aplikasi namun dapat dilakukan secara online yang mencakup jasa delivery order 
atau pengiriman barang dan makanan. Lamongan merupakan salah satu kota yang sudah mengembangkan usaha jasa pelayanan delivery order tersebut. Banyaknya masyarakat Lamongan yang terbantu dengan adanya jasa tersebut sehingga saat ini terdapat beberapa usaha jasa pelayanan delivery order yang baru dan mulai berkembang.

Para pelaku usaha jasa pelayanan delivery order di Lamongan saling berkompetisi dan ingin menjadi jasa pelayanan delivery order yang terbaik. Berbagai program dan bonus telah diberikan pengusaha kepada pelanggan untuk menarik minat pelanggan agar menggunakan jasa pelayanan delivery order milik mereka. Kepuasaan pelanggan tentunya menjadi hal yang paling utama dilakukan agar pelanggan melakukan repeat order kepada mereka. Apalagi sejak Grab mulai masuk ke kota Lamongan menjadikan persaingan mendapatkan pelanggan semakin kompetitif.

Hal inilah yang mendasari dilakukan penelitian analisis kepuasan pelanggan jasa pelayanan delivery order agar pengusaha jasa tersebut dapat mengetahui kepuasan pelanggan terhadap pelayanan yang telah diberikan. Tujuan lainnya adalah untuk mengetahui besar kesenjangan (gap) antara harapan dengan kenyataan dari pelayanan yang diterima pelanggan jasa delivery order. Harapan yang ingin dicapai dengan penelitian ini adalah adanya evaluasi dan langkah program selanjutnya bagi jasa pelayanan delivery order agar dapat meningkatkan kualitas pelayanan kepada pelanggan.

\section{Metode Service Quality}

Model pengukuran kualitas pelayanan terdiri dari berbagai macam. Namun, metode Service Qualitymerupakan metode yang paling banyak digunakan (Wisniewski, 2001).Kualitas jasa (Service Quality) adalah suatu ukuran tingkat layanan yang diberikan sesuai denganekspektasi pelanggan, dengan tingkat pelayanan yang diberikansecara maksimal akan memberikan kepuasan konsumen. Limadimensi Service Quality meliputi: (Oey, 2014).

1. Bukti langsung (tangible), yang meliputi fasilitas fisik, perlengkapan, pegawai, dan sarana komunikasi.

2. Keandalan (reliability), yakni kemampuan memberikan pelayanan yang dijanjikan dengan segera, akurat, dan memuaskan.

3. Daya tanggap (responsiveness), yaitu keinginan para staf dan karyawan untuk membantu para pelanggan dan memberikan pelayanan dengan tanggap.

4. Jaminan (assurance), yang mencakup pengetahuan, kemampuan, kesopanan, dan sifat yang dapat dipercaya yang dimiliki para staf, bebas dari bahaya, risiko, atau keragu-raguan.

5. Empati (emphaty), yang meliputi kemudahan dalam melakukan hubungan, komunikasi yang baik, perhatian pribadi, dan memahami kebutuhan para pelanggan. (Parasuraman, et all, 1988).

\section{Kepuasan Pelanggan}

Kepuasan adalahtanggapan atau responpelanggan terhadap evaluasi persepsi atasperbedaan antara harapan awal sebelum pembelian (pelayanan) dan kinerjaaktual produk sebagaimana dipersepsikan setelah memakai atau mengkonsumsi produkbersangkutan (Tjiptono, 2008 : 169). Menurut Nasution (2004:102) Pelanggan suatu perusahaanadalah orang yang membeli dan menggunakan produk suatu perusahaan. Menurut Kotler (1997) 
kepuasan pelanggan adalah peringkat kondisi yang dirasakan konsumen sebagai hasil perbandingan dari pelayanan yang diterima dengan apayang diharapkan. Jadi kepuasan pelanggan dapat disimpulkansebagai perbandingan dari kualitas jasa pelayanan yang diterima berbanding dengan ekspektasikualitas dari konsumen.

\section{Jasa Delivery Order}

Layanan pesan antar atau delivery order merupakan salah satu program untuk menunjang citra bisnis dengan memberikan pelayanan terbaik kepada pelanggan. Jenis-jenis usaha yang memberikan jasa delivery order adalah sebagai berikut restaurant, bengkel, toko, perkantoran, pabrik dan lainnya mencoba menghadirkan layanan ini kepada konsumennya. Layanan pesan antar ini membutuhkan biaya dan tenaga yang besar, sehingga hanya sedikit peursahaan yang mau berinvestasi untuk jasa layanan tersebut(Kompas, 2007)..

Usaha jasa layanan delivery order memiliki tugas untuk mengantarkan barang pesanan yang dipesan ke pada konsumen. Modal yang utama dalam menjalankan usaha ini adalah alat tranportasi misalnya motor dan mobil. Kunci utama dalam menjalankan jenis bisnis ini adalah memperluas jaringan agar mendapat pelanggan yang banyak.

Usaha jasa layanan delivery order ini merupakan usaha yang sangat menjanjikan karena dapat membuka lapangan pekerjaan dan menghasilkan keuntungan yang banyak. Pada tahun 2018 jumlahnya semakin banyak dan bemacam - macam. Bahkan ada yang dijalankan oleh perorangan dan juga perusahaan.

\section{METODELOGI PENELITIAN}

Populasi dari penelitian ini adalah seluruh pelanggan jasa delivery order yang berada di kota Lamongan, tetapi dikarenakan keterbatasan waktu dan biaya tidak semuapelanggan dilibatkan. Sampel yang digunakan adalah pelanggan yang menggunakan jasa delivery order kota Lamongan yang merupakan civitas akademik di Universitas Islam Lamnongan.

Pengolahan dan analsis data dalam penelitian ini digunakan beberapa analisis pengujian data, yaitu:

1. Validitas, untuk mengetahui sejauh mana ketepatan suatu alat ukur melakukan fungsi ukurnya

2. Reliabilitas, untuk mengukur suatu kuesioner yang merupakan indikator dari variabel atau konstruk

3. Analisis Gap, untuk mengetahui besarnya kesenjangan antara harapan yang dinginkan pelanggan dengan kenyataan pelayanan yang dirasakan pelanggan.

\section{HASIL DAN PEMBAHASAN Uji Validitas}

Analisis uji validitas dapat dilakukan dengan memperhatikan nilai dalam tabel item-total statistics bagian corrected itemtotal correlation. Data yang diolah berjumlah 102, sehingga $\mathrm{v}=\mathrm{n}-2=102-2$ $=100$ dengan $\alpha=5 \%$. Nilai $\mathrm{r}$ tabel adalah 0.195. Uji validitas data berdasarkan butir pertanyaan dalam setiap indikator memliki nilai yang sudah lebih besar jika dibandingkan dengan nilai $r$ tabel. Hal ini mengindikasikan bahwasemua item pertanyaan untuk indikator Tangibel, Reliability, Responsiveness, Assurance, Emphaty sudah valid. 


\section{Uji Reliabilitas}

Analisis uji reliabilitas dapat dilakukan dengan memperhatikan nilai Alfa Cronbach dalam tabel Reliability Statistics.

Tabel 1. Hasil Uji Reliabilitas

\begin{tabular}{|l|c|c|c|}
\hline $\begin{array}{c}\text { Instrumen } \\
\text { Variabel }\end{array}$ & $\begin{array}{c}\text { Alfa } \\
\text { Cron- } \\
\text { bach }\end{array}$ & $\begin{array}{c}\text { Batas } \\
\text { Relia- } \\
\text { bilitas }\end{array}$ & Ket \\
\hline Tangible & 0,877 & 0,7 & Reliabel \\
\hline Reliability & 0,775 & 0,7 & Reliabel \\
\hline $\begin{array}{l}\text { Responsive- } \\
\text { ness }\end{array}$ & 0,764 & 0,7 & Reliabel \\
\hline
\end{tabular}

\begin{tabular}{|l|l|l|l|}
\hline Assurance & 0,865 & 0,7 & Reliabel \\
\hline Emphaty & 0,847 & 0,7 & Reliabel \\
\hline
\end{tabular}

Hal ini menandakan bahwa semua variabel yang digunakan dalam instrumen kuisioner penelitian ini sudah reliabel.

\section{Analisis Gap}

Berikut ini adalah hasil analisa terhadap kesenjangan setiap butir pertanyaanpada kuesioner yang telah diisi pelanggan:

Tabel 2. Hasil Analisis Gap

\begin{tabular}{|c|l|c|c|c|c|}
\hline No & \multicolumn{1}{|c|}{ Butir Pertanyaan } & Dimensi & $\begin{array}{c}\text { Rata- } \\
\text { rata } \\
\text { Harapan }\end{array}$ & $\begin{array}{c}\text { Rata-rata } \\
\text { Kenyataan }\end{array}$ & Gap \\
\hline 1 & $\begin{array}{l}\text { Ketersediaan Informasi Program dan } \\
\text { Produk di Account Sosial Media }\end{array}$ & Tangible & 3,696 & 2,159 & $-1,536$ \\
\hline 2 & Kualitas penampilan petugas & Tangible & 3,696 & 2,406 & $-1,290$ \\
\hline 3 & $\begin{array}{l}\text { Kesopanan petugas saat mengantarkan } \\
\text { orderan }\end{array}$ & Tangible & 3,739 & 2,855 & $-0,884$ \\
\hline 4 & Kualitas pengantaran orderan & Tangible & 3,725 & 3,188 & $-0,536$ \\
\hline 5 & Kemudahan format order & Reliability & 3,768 & 2,913 & $-0,855$ \\
\hline 6 & $\begin{array}{l}\text { Kemudahan menghubungi petugas } \\
\text { pelaksana order }\end{array}$ & Reliability & 3,652 & 2,116 & $-1,536$ \\
\hline 7 & $\begin{array}{l}\text { Ketersediaan customer service untuk } \\
\text { menerima keluhan }\end{array}$ & Reliability & 3,783 & 3,116 & $-0,667$ \\
\hline 8 & Kecepatan respon terhadap order & Responsiveness & 3,812 & 2,652 & $-1,159$ \\
\hline 9 & Kecepatan penyelesaian order & Responsiveness & 3,739 & 2,957 & $-0,783$ \\
\hline 10 & $\begin{array}{l}\text { Kecepatan dan keakuratan order yang sesuai } \\
\text { dengan pesanan }\end{array}$ & Responsiveness & 3,797 & 2,754 & $-1,043$ \\
\hline 11 & $\begin{array}{l}\text { Kemampuan dan kesigapan petugas dalam } \\
\text { menghadapi perubahan pesanan pelanggan }\end{array}$ & Responsiveness & 3,812 & 2,580 & $-1,232$ \\
\hline 12 & Kesesuaian petugas menjalankan pesanan & Assurance & 3,812 & 2,406 & $-1,406$ \\
\hline 13 & $\begin{array}{l}\text { Ketrampilan petugas dalam memberikan } \\
\text { pelayanan }\end{array}$ & Assurance & 3,217 & 2,261 & $-0,957$ \\
\hline 14 & $\begin{array}{l}\text { keyakinan dan ketepatan pembayaran sesuai } \\
\text { dengan invoice }\end{array}$ & Assurance & 3,725 & 2,174 & $-1,551$ \\
\hline 15 & $\begin{array}{l}\text { Kemampuan petugas dalam memberikan } \\
\text { informasi menu dan harga }\end{array}$ & Assurance & 3,203 & 2,391 & $-0,812$ \\
\hline 16 & $\begin{array}{l}\text { Kesabaran petugas dalam menerima } \\
\text { keluhan dari pelanggan }\end{array}$ & Emphaty & 3,725 & 2,261 & $-1,464$ \\
\hline 17 & $\begin{array}{l}\text { Ketersediaan Informasi invoice yang } \\
\text { diberikan melalui whatsapp }\end{array}$ & Emphaty & 3,754 & 2,014 & $-1,739$ \\
\hline 18 & $\begin{array}{l}\text { Keramahan petugas dalam menghubungi } \\
\text { pelanggan }\end{array}$ & Emphaty & 3,638 & 2,377 & $-1,261$ \\
\hline & & & & \\
\hline
\end{tabular}




\begin{tabular}{|c|c|c|c|c|c|}
\hline No & Butir Pertanyaan & Dimensi & $\begin{array}{c}\text { Rata- } \\
\text { rata } \\
\text { Harapan }\end{array}$ & $\begin{array}{c}\text { Rata-rata } \\
\text { Kenyataan }\end{array}$ & Gap \\
\hline 19 & $\begin{array}{l}\text { Kesediaan petugas untuk mengkonfirmasi } \\
\text { pesanan setelah mengantarkan orderan }\end{array}$ & Emphaty & 3,768 & 2,638 & $-1,130$ \\
\hline
\end{tabular}

Kualitas kepuasaan pelanggan digambarkan oleh nilai gap antara penilian kenyataan pelayananterhadap pelanggan dengan penilaianharapanterhadap kriteria yang sama. Nilai gap negatif menunjukkan kualitas pelayanan suatu kriteria kurang baik sehingga perlu ditingkatkan. Idealnya, nilai gap antara persepsi danharapan adalah nol. Hal ini menunjukkan harapan pelanggan terhadap suatukriteria pelayanan adalah sama dengan persepsi pelanggan terhadap kriteria yangsama.

Semakin besar nilai negatif suatu gap pada suatu kriteria pelayanan, semakinbesar pula prioritas peningkatan kualitas pelayanan dari kriteria pelayanan tersebut.

Berdasarkan perhitungan data yang ditunjukkan pada Tabel 2, nilai gap negatif tertinggi adalah pada kriteriaKetersediaan Informasi invoice yang diberikan melalui whatsappyaitu 1,73 dan keyakinan dan ketepatan pembayaran sesuai dengan invoice yaitu 1,551. Kedua hal ini masuk dalam dimensi Emphaty dan dimensi Assurance. Hal ini harus diperhatikan oleh pengelola usaha delivery order agar dilakukan evaluasi terhadap kedua dimensi tersebut. Apalagi jika diperhatikan kedua hal tersebut berkaitan dengan invoice pembayaran yang harus dilakukan oleh pelanggan. Jika hal kedua hal ini dievaluasi dan ditingkatkan pelayanannya maka nilai gap nya akan semakin kecil dan dapat pelanggan akan semakin percaya terhadap jasa pelayanan delivery order di kota Lamongan.

\section{PENUTUP}

Kesimpulan yang dihasilkan dari penelitian ini adalah sebagai berikut :

1. Semua dimensi Service Quality memiliki nilai gap yang negatif sehingga semua dimensi masih memerlukan perbaikan

2. Dua indikator yang memiliki nilai gap negatif tertinggi dan harus segera diperbaiki adalah dimensi Emphaty untuk kriteria ketersediaan informasi invoice yang diberikan melalui whatsapp dan dimensi Assurance untuk kriteria keyakinan dan ketepatan pembayaran sesuai dengan invoice.

Saran untuk penelitian selanjutnya adalah batasan sampel yang diambil agar dapat diperluas sehingga hasil yang didapatkan lebih valid dan dapat mewakili seluruh pelanggan di kota Lamongan.

\section{DAFTAR PUSTAKA}

Kompas. 2007. Peluang Bisnis dalam Jasa Layanan Pesan Antar(Online)(http://www.kerjau saha.com/2014/03/membangunbisnis-jasa-layanan-pesan.html), (diakses 28 Januari 2018)

Kotler, P., Marketing Managemen: Analysis, Planning, Implementation and Control, Prentice Hall Inc, New Jersey, 1997.

Oey, Eka Cipta Wijaya. 2014. Pengaruh Kualitas Layanan terhadap 
Kepuasan Pelanggan dalam Membentuk Loyalitas Pelanggan pada Pengguna Jasa Garuda Indonesia di Surabaya. Jurnal Ilmiah Mahasiswa Universitas Surabaya Vol. 3 No. 1

Parasuraman, A., V. A. Zeithaml, dan L.L Berry, 1988, SERVQUAL: A Multiple Item Scale for Marketing Customer Perceptions of Service Quality. Journal of Retailing, Vol. 64.

Tjiptono, Fandy dan Gregorius Chandra.2005. Service Quality dan Satisfaction. Yogyakarta: Penerbit Andi.

Wisniewski, M. 2001. 'Using SERVQUAL to assess customer satisfaction with public sector services". Managing Service Quality, Vol. 11 No. 5, pp. $380-$ 388. 